\title{
REVIEWS
}

\section{Rainforest, Savana and High Mountain in Bolivia ${ }^{1}$}

The vegetation of South America has been mapped on small scales many times (Drude, Engler, Schimper, Denis, Rübel, etc.). Although these various representations do not completely coincide, they have left with us a fairly coherent picture of the continent's plant cover. We have, on the other hand, a more intimate knowledge of some small or local areas for which data of a quantitative nature are available. Guillermo Mann now offers us a general view of plant and animal life in Bolivia. The maps are in no way an improvement over preceding ones, some of which are indeed a good deal more precise in their outlines (but maybe unjustifiably so) Nor can it be claimed that any description of plant community adds considerably to our previous knowledge of it. The merits of this book lie elsewhere.

In the first place the contents do conform to the title, which is not always so of books that advertise themselves as "ecological." An authentically ecological point of view prevails throughout. Moreover, the author shows an awareness of the shifts of emphasis that have taken place in biological thinking since Warming and Schimper's time, as he also makes us aware of the many challenges made by these early vegetationists which have been forgotten by more recent investigators.

The book consists of three parts: I selva, II savana, III high mountain. The analysis is a very symmetrical and logical one which makes excellent reading and offers easy cross-reference. In each part the first chapter concerns spatial extension; the second describes physiognomy, life-cycles, adaptive features, and ecological factors; the third outlines variations within the formation (especially in ecotonal areas) and successional dynamics.

The very symmetry of such treatment results in chapters of somewhat uneven value and an approach which is sometimes a little abstract. However, the numerous examples of plants and animals actually observed and photographed by the author and sketched in drawings by Serena Mann de Pfeil give each chapter the substance and the reality which it would otherwise lack. In his preface, Mann states that his object is to convey "a first glance of the prevailing harmonies" of the Bolivian environment and of its "larger biotic units." His book he

1 Mann F., Guillermo. 1951. Esquema ecologico de selva, sabana y cordillera en Bolivia. 236 pp. Universidad de Chile, Facultad de Filosofia, Instituto de Geografia, Publ. No. 3. considers an "ecological guide." Its usefulness is extended to a non-Spanish-reading audience by the interpolation of an English and a German summary, which are quite substantial. However, the latter contain only the theoretical conclusions and the reader will still have to refer to the Spanish text for a citation of examples and a concrete description of organisms and phenomena. The English wording and syntax are not always perfect and the spelling is frequently in error, but only rarely do these faults actually disguise the author's meaning (amphibiotic for amphibious).

It would hardly be fair to say that this sweeping review of a relatively large segment of the tropical world is superficial, as it could hardly be otherwise unless the book were five times its present length. Rather it remains to evaluate the accuracy and consistency of the concepts applied and to judge the sharpness of the picture which is conveyed.

Clements and Shelford's terminology and method are adhered to, and some of their keywords are re-defined. However, to this are added so many physiognomic-structural and autecological observations (in the tradition of Warming, Schimper and Hesse) that the "bio-ecological" framework does not actually prevail. An attempt is made, for instance, to recognize biomes, but is hardly followed through. In fact, it is clear that three formations are being studied, and within them only the broadest ecological units are recognized and then are tagged with ordinary vernacular names, such as "flooded savana," "forest pools," etc. The life-form, structure and abundance of dominants is very clearly described in each case. The author repeatedly mentions their influence on climate, whereas he evidently means microclimate (the evolution of meteorological elements within the community). However, the physiognomic picture is always completed by a description of the adaptations which are most typical of the formation or community, irrespective of the spatial importance of the organisms in question.

Although he seems to accept wholeheartedly the monoclimax theory and cites many successional sequences in both xerosere and hydrosere, the author shows awareness of the many factors that retard and inhibit succession and describes many edaphically-controlled communities.

The brief bibliography at the end of the book is hardly cited in the text. One feels that the author is familiar with many other works not mentioned here and he would have in- 
creased the usefulness of his book by listing them for reference and citing them in the proper place in the text.

As it stands, the book is certain to offer much stimulation to further research and exploration. The descriptions will be developed by local study and the principles and laws will be tested by comparison, discussion and new investigations.

Department of Botany, Pterre Dansereau

UNIVERSity OF Michigan, Ann ARBor, Michigan

\section{INTEGRATION OF THE ECOSPECIES ${ }^{1}$}

The eternally disputed definition of species is very sharply focused in Jens Clausen's book, "Stages in the evolution of plant species." The outstanding merit of this work is that it summarizes very lucidly the experiments on the nature of species which Hall had begun but which are principally Clausen's own work and that of his collaborators David D. Keck and Wm. M. Hiesey at the Carnegie Institution of Washington's Department of Plant Biology in Stanford, California. The past decade has been a very fruitful one for this group, as the essentials and much of the detail of their experimental work have been made known in print. The soundness of their method, the thoroughness of their investigations and the variety of their respective backgrounds offered unique guarantees of original and significant research. Their three book-length memoirs and their many shorter papers had provided us with a great wealth of new materials and many leads to new interpretations. The present book goes a step beyond this and outlines Clausen's (and presumably his collaborators') emergent concept of speciation. This is far-reaching indeed, although the author does not pretend to review the whole field of experimental taxonomy, even less the more general topic of evolution. In fact, it justifies its title perfectly by casting complete emphasis on experimentally known cases of perfect to imperfect to inadequate isolation of taxa in the Western North American environment. Some of the author's earlier work in Northwestern Europe is also quoted, as are Brainerd and Gershoy's in Eastern North America. But no one will quarrel with Clausen's dwelling principally on what he knows best: a central Californian transect from the Pacific across the coastal ranges and inner valleys to the slopes and summits of the Sierra Nevada, thence down to the deserts of the Great Basin. Such a transect lends itself extremely well to a test of evolutionary processes as it provides strongly contrasting environmental backgrounds at close intervals. Even though such telescoping is not unique, it is in many ways peculiar and the rates of change and the

1 Clausen, Jens. 1951. Stages in the evolution of plant species. viii +206 pp., 76 figs., Ithaca: Cornell University Press, $\$ 3.75$. very mechanisms observed are sure to be quite different in other parts of the world with broad instead of narrow life zones. Stebbins for instance (Am. Nat., 86 (826) : 34, 1952) ventures to "predict that the diversity of ecotypes of individual species, when investigated will prove to be considerably less" in the Eastern States than in California.

The book consists of eight chapters. The first two offer a brief historical perspective in which the growing influence of genetics on taxonomy is emphasized. The principal currents are outlined: Darwin's keen observations of variation in nature and its obedience to natural selection; the experimental approach and discovery of the mechanics of heredity by Mendel's successors. These two traditions, which to some extent had followed separate courses, are joined harmoniously in Turesson's work. The often overlooked evolutionary ideas of Linnaeus in his later years are quoted as marking the beginning of a "modern" point of view. Jordan is credited with the discovery of the local population.

This is the subject of the third chapter, "The local population as the basic evolutionary unit." Here the author's working principles are clearly stated: "It is at the level of the local population that all of the selective forces act upon the genetic resources of the population." This statement is well illustrated and substantiated by examples from the genera Layia, Viola, Potentilla, and Achillea. Following the best in taxonomic tradition, intra-population and interpopulation variations are compared and found to be of a different order of magnitude (p. 26). However, these analyses are always made in the light of the deeper-lying physiological responses which are elicited by the heredity vs. environment contest. Thus: "It is probable that the intrapopulation variation enables a species to tolerate periodic variations in the climate at any one locality."

These various points are strikingly illustrated by experimental data, the conclusiveness of which is quite incontestable. One might wish, however, that Clausen's rejection of other techniques for estimating populations "growing in the wild and therefore subjected to uncontrolled modifications in many environments" were the object of further discussion. The work of Edgar Anderson, Fassett, and Woodson is not men- 